\title{
Spatiotemporal pattern of COVID-19 spread in Brazil
}

\author{
Marcia C. Castro', , Sun Kim, Lorena Barberia ${ }^{2}$, Ana Freitas Ribeiro ${ }^{3,4}$, Susie Gurzenda $^{1}$, Karina Braga Ribeiros, \\ Erin Abbott ${ }^{6}$, Jeffrey Blossom ${ }^{6}$, Beatriz Rache ${ }^{7}$, Burton H. Singer ${ }^{8}$ \\ ${ }^{1}$ Department of Global Health and Population, Harvard T. H. Chan School of Public Health, Boston, MA, USA. ${ }^{2}$ Department of Political Science, University of São Paulo (USP),

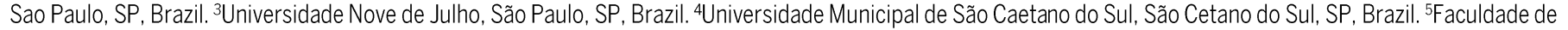 \\ Ciências Médicas da Santa Casa de São Paulo, Department of Collective Health, São Paulo, SP, Brazil. ${ }^{6}$ Center for Geographical Analysis, Harvard University, Cambridge, \\ MA, USA. ${ }^{7}$ Instituto de Estudos para Políticas de Saúde (IEPS), São Paulo, SP, Brazil. ${ }^{8}$ Emerging Pathogens Institute, University of Florida, Gainesville, FL, USA. \\ *Corresponding author. Email: mcastro@hsph.harvard.edu
}

\begin{abstract}
Brazil has been severely hit by COVID-19, with rapid spatial spread of both cases and deaths. We use daily data on reported cases and deaths to understand, measure, and compare the spatiotemporal pattern of the spread across municipalities. Indicators of clustering, trajectories, speed, and intensity of the movement of COVID-19 to interior areas, combined with indices of policy measures show that while no single narrative explains the diversity in the spread, an overall failure of implementing prompt, coordinated, and equitable responses in a context of stark local inequalities fueled disease spread. This resulted in high and unequal infection and mortality burdens. With a current surge in cases and deaths and several variants of concern in circulation, failure to mitigate the spread could further aggravate the burden.
\end{abstract}

Brazil is the only country that, with a population larger than 100 million, has a universal, comprehensive, and free of charge health care system. Over three decades, this system contributed to reducing inequalities in access to health care and outcomes (1). It also facilitated the management of previous public health emergencies, such as the HIV/AIDS pandemic (2). Despite recent cuts in the health budget (3), it was expected that Brazil's health system would place the country in a good position to mitigate the COVID-19 pandemic. With national coordination and through a vast network of community health agents, actions adapted to existing local inequalities (i.e., regional distribution of physicians and hospital beds) could have been implemented (4). However, Brazil is one of the countries most severely hit by COVID-19. As of March 11, 2021, 11,277,717 cases and 272,889 deaths have been reported. Those represent $9.5 \%$ and $10.4 \%$ of the worldwide cases and deaths, respectively; yet, Brazil shares only $2.7 \%$ of the world's population. In late May, 2020, Latin America was declared the epicenter of the COVID-19 pandemic, mainly because of Brazil. Since June 7, 2020, Brazil ranks $2^{\text {nd }}$ in deaths worldwide.

In Brazil, the federal response has been a dangerous combination of inaction and wrongdoing, including the promotion of chloroquine as treatment despite a lack of evidence (5, 6 ). Without a coordinated national strategy, local responses varied in form, intensity, duration, and start and end times, to some extent associated with political alignments $(7,8)$. The country has seen very high attack rates (9) and disproportionally higher burden among the most vulnerable $(10,11)$, illuminating local inequalities (12). Following multiple introductions of SARS-CoV-2, Brazil had an initial epidemic phase (February 15 to March 18, 2020) with restricted circulation (13), preceded by undetected virus circulation (14). While the initial spread was determined by existing socioeconomic inequalities, the lack of a coordinated, effective, and equitable response likely fueled the widespread spatial propagation of SARS-CoV-2 (12). The goal of this study was to understand, measure, and compare the pattern of spread of COVID-19 cases and deaths in Brazil at fine spatial and temporal scales. We use daily data from State Health Offices covering the period from epidemiological week 9 (February 2329) to week 41 (October 4-10).

In all states, it took less than a month between the first case and the first death; only 11 days in Amazonas and 21 in São Paulo (table S1). Epidemiological curves for Brazil (fig. S1) hide distinct patterns of initial reporting, propagation, and containment of SARS-CoV-2 across administrative units. As states and cities imposed and relaxed restrictive measures at different times, population mobility facilitated the circulation of the virus and acted as a trigger of disease spread (15). Figure 1, A and B, show that cumulative cases and deaths, respectively, per 100,000 people were not uniformly distributed across municipalities. We used the space-time scan statistic (16) to identify areas that significantly recorded a high number of cases (Fig. 1C and table S2) or deaths (Fig. 1D and table S3) over a defined period.

Deaths clustered about a month before cases. This likely reflects problems in surveillance, data reporting, and low testing capacity. The first significant cluster of COVID-19 deaths started on May 18 (Fig. 1D, \#5), centered around Recife (capital of Pernambuco). Five other clusters of deaths occurred before the first cluster of cases was observed on June 16 (Fig. 1C, \#7). Among those are clusters around Fortaleza and Rio de Janeiro (capital cities of Ceará and Rio de Janeiro, 
respectively), and in a large area including Amazonas, Pará, and Amapá, states that have a disproportionally lower hospital capacity. Amazonas (whose capital is Manaus) has the highest mortality per 100,000 people in the country, more than double the rate for Brazil. By October, about $76 \%$ of its population was estimated to have been infected $(9,17)$. Except for one cluster in August (Fig. 1D, \#1), the duration of death clusters did not reduce over time, ranging from 10 to 13 days. This is different than what was observed in South Korea, where successful containment reduced the duration and the geographic extent of clusters over time (18). A similar pattern was observed for COVID-19 cases (Fig. 1C). In the center and southern areas, clusters occurred later (August and September), corroborating a regional pattern of propagation of SARS-CoV-2 (19).

To understand and compare how COVID-19 cases and deaths spread across Brazil we calculated the geographic center of the epidemic. Trajectories of the center by epidemiological week show that after the introduction in São Paulo, both cases (Fig. 2A and movie S1) and deaths (Fig. 2B and movie S2) progressively moved north until week 20 (starting May 10), when the epidemic started to recede in Amazonas and Ceará, but gained force in Rio de Janeiro and São Paulo. Comparing trajectories in each state (fig. S2) we calculated a ratio of the distance the center moved each week to the distance between the capital city and the most distant municipality (tables S4 and S5). In eight states the median weekly ratio for deaths was larger than cases (Fig. 2C), suggesting a faster movement of the focus of deaths.

On average, it took 17.3 and 32.3 days to reach 50 cases and deaths, respectively. However, in four states deaths accumulated to a 50-count first (Fig. 2D), and in Amazonas, Ceará, and Rio de Janeiro the difference between the time it took for cases and deaths to reach a 50-count was 6,1 , and 3 days, respectively (table $\mathrm{S} 1$ ). This short interval suggests undetected (and thus unmitigated) introduction and propagation of the virus for some time. This was confirmed in Ceará (20) where a retrospective epidemiological investigation revealed that the virus was already circulating in January. Also, if the initial cases occurred in high-income areas, it is possible that consultations in private practices were not reported into national systems of the Ministry of Health (20) and remained silent to the surveillance system. In addition, testing capacity in Brazil was limited, and the first diagnostic RT-PCR test kits started to be produced in the country only in March. Although efforts of retrospective investigation were not scaledup in the country, a comparison of standardized rates of cases and deaths per 100,000 people (Fig. 2E) show that in 11 states the death toll was larger than incidence, including Amazonas, Ceará, and Rio de Janeiro.

To quantitatively measure the intensity of the spread of COVID-19 cases and deaths over time we used the locational
Hoover Index (HI) (21, 22). Values closer to 100 indicate concentration in few municipalities, while those close to zero suggest more homogeneous spreading. If containment measures were effective, we would expect the index to decline slowly, remaining relatively high over time. Also, if measures were effective to avoid a collapse of the hospital system, we would expect a higher index for deaths, compared to cases. Figure 3A shows the HI for Brazil, and a clear trend toward extensive spread for both cases and deaths until about week 30 (July 19-25). The pattern, however, varied across states. In the first week with reported events, Amazonas, Roraima, and Amapá had HI below 50 for both cases and deaths. This suggests either undetected circulation of the virus before initial reports (and therefore when reporting started there was already a large fraction of the population that had been infected), or fast and multiple introductions of the virus immediately followed by rapid spatial propagation (tables $\mathrm{S} 6$ and S7).

Overall, the spread of COVID-19 was fast. By week 24 (June 7-13) and 32 (August 2-8), all states had HI for cases and deaths, respectively, lower than 50. In nine states, including Amazonas, Amapá, Ceará, and Rio de Janeiro, the spreading of deaths was faster than cases over several weeks (Fig. 3B), with some overlap with the time when clusters were observed in those areas (Fig. 1, C and D). Figure 3, C and D, show the first and last weekly $\mathrm{HI}$ for cases and deaths by states and there are marked contrasts in HI trajectory (tables S6 and S7). By week 41 (October 4-10), COVID-19 deaths in Amapá $(\mathrm{HI}=31.3)$ had moved to the interior faster than cases $(\mathrm{HI}=42.9)$. Rio de Janeiro had the most intense interiorization of both cases $(\mathrm{HI}=14.9)$ and deaths $(\mathrm{HI}=21.9)$, followed by Amazonas (HI cases=20.2, HI deaths $=30.4)$. Both experienced a shortage of ICU beds, but Amazonas has smaller availability (about 11 ICU beds per 100,000 people vs 23 in Rio de Janeiro), all concentrated in the capital city, Manaus. As the virus moved to the interior a higher demand for scarce and distant resources intensified, not all of which were fulfilled in time to prevent fatalities (23). In Rio de Janeiro, political chaos compromised a prompt and effective response. Leaders were immersed in corruption accusations, the governor was removed from office and face an impeachment trial, and the Secretary of Health was changed three times between May and September, one of whom was arrested (24). In contrast, although Ceará also experienced a near-collapse of the hospital system late April to mid-May, and had silent circulation of the virus more than a month before the first case was officially reported (20), it ranked $6^{\text {th }}$ in movement of cases $(\mathrm{HI}=31.3)$, but was the antepenultimate in deaths $(\mathrm{HI}=64.5)$. This suggests that even with the continued spread of the virus, local actions were successful in preventing fatality. No state had HI for cases higher than 50 by week 41, revealing an extensive pattern of disease spread toward the interior. 
Overall, a higher percentage of COVID-19 cases and deaths were observed outside capital cities in weeks 20 (May 10-16) and 22 (May 24-30), respectively (Fig. 4A), with varied patterns across states (table S1). Rio Grande do Sul, Santa Catarina, and Paraná, all in the South region, had earlier and concurrent shifts in cases and deaths (in March), and this was the last region to show a major surge in COVID-19. In Rio de Janeiro and Amazonas, the shift in deaths was much later than cases, 10 and 8 weeks, respectively.

To better capture policies adopted at the national and local levels and their associations with movement of COVID-19 toward the interior of states, we used three indicators, the Stringency Index (STR), the Containment Index (CTN - all policies in STR except for the use of masks), and the Social Distancing Index (SD - based on mobile devices). Because states introduced measures at different times with various duration, national indices hide much variation (Fig. 4B). We observed expected correlations (table S8) between policy indicators and $\mathrm{HI}$ for cases and deaths (Fig. 4C), but a positive correlation between $\mathrm{HI}$ and the distance by which the national geographical center of cases shifted weekly. This suggests a pattern of progressive concentration of cases and deaths in few but widespread areas. Considering each state (fig. S3), Amapá showed a negative correlation between STR and $\mathrm{HI}$ for deaths, indicating that policy measures failed to prevent the movement of deaths (this was the only state where deaths moved to the interior faster than cases by week 41; Fig. 3D).

We used hierarchical clustering analysis (25) in an attempt to group states into categories based on measures that captured the overall COVID-19 mortality burden, intensity of transmission, speed of COVID-19 deaths toward the interior of states, and adoption of distancing measures (Fig. 4D). Categories 3 and 4 include the top 10 states in deaths/100,000 people, as well as those that observed the first spatiotemporal clustering of deaths, and fast reporting and movement of deaths. Category 2 has the highest number of contiguous states and the lowest death burden by week 41. However, all categories combine states with different levels of inequality and distinct political alignment.

In summary, our results highlight the fast spread of both cases and deaths of COVID-19 in Brazil, with distinct patterns and burden by state. They demonstrate that no single narrative explains the propagation of the virus across states in Brazil. Instead, layers of complex scenarios interweave, resulting in varied and concurrent COVID-19 epidemics across the country. First, Brazil is large and unequal, with disparities in quantity and quality of health resources (e.g., hospital beds, physicians), and income (e.g., an emergency cash transfer program started only in June 2020, and by November $41 \%$ of the households were receiving it). Second, a dense urban network that connects and influences municipalities through transportation, services, and business (26) was not fully interrupted during peaks in cases or deaths. Third, political alignment between governors and the president had a role in the timing and intensity of distancing measures (7), and polarization politicized the pandemic with consequences to adherence to control actions (27). Fourth, SARS-CoV-2 was circulating undetected in Brazil for more than a month (20), a result of the lack of well-structured genomic surveillance (28). Fifth, cities imposed and relaxed measures at different moments, based on distinct criteria, facilitating propagation (15). Our findings speak to those issues, but also show that some states were resilient, such as Ceará, while others that comparatively had more resources failed to contain the propagation of COVID-19, such as Rio de Janeiro.

In such a scenario, prompt and equitable responses, coordinated at the federal level, are imperative to avoid fast virus propagation and disparities in outcomes (12). Yet, the COVID19 response in Brazil was neither prompt nor equitable. It still isn't. Brazil is currently facing the worst moment of the pandemic, with a record number of cases and deaths, and near collapse of the hospital system. Vaccination has started but at a slow pace due to limited availability of doses. A new variant of concern (VOC), which emerged in Manaus (P1) in December, is estimated to be 1.4-2.2 times more transmissible, and able to evade immunity from previous non-P1 infection (29). That variant is spreading across the country. It became the most prevalent in circulation in six of eight states where investigations were performed (30). As of March 11, 2021, Brazil already reported $40 \%$ of the total COVID- 19 deaths that occurred in 2020. In January 2021, Manaus witnessed a spike in cases and hospitalizations, a collapse of the hospital system, including a shortage of oxygen for patients (31). The death toll is unbearable, as Manaus already recorded 39.8\% more COVID-19 deaths in 2021 than in 2020. Without immediate action, this could be a preview of what is yet to happen in other localities in Brazil. Without immediate containment, coordinated epidemiological and genomic surveillance measures, and an effort to vaccinate the largest number of people in the shortest possible time, the propagation of P1 will likely resemble the patterns here demonstrated, leading to unimaginable loss of lives. Failure to avoid this new round of propagation will facilitate the emergence of new VOCs, isolate Brazil as a threat to global health security, and lead to a completely avoidable humanitarian crisis.

\section{REFERENCES AND NOTES}

1. M. C. Castro, A. Massuda, G. Almeida, N. A. Menezes-Filho, M. V. Andrade, K. V. M de Souza Noronha, R. Rocha, J. Macinko, T. Hone, R. Tasca, L. Giovanella, A. M. Malik, H. Werneck, L. A. Fachini, R. Atun, Brazil's unified health system: The first 30 years and prospects for the future. Lancet 394, 345-356 (2019). doi:10.1016/S0140-6736(19)31243-7 Medline

2. A. Berkman, J. Garcia, M. Muñoz-Laboy, V. Paiva, R. Parker, A critical analysis of the Brazilian response to HIV/AIDS: Lessons learned for controlling and mitigating the epidemic in developing countries. Am. J. Public Health 95, 1162-1172 (2005). doi:10.2105/AJPH2004.054593 Medline 
3. A. Massuda, T. Hone, F. A. G. Leles, M. C. de Castro, R. Atun, The Brazilian health system at crossroads: Progress, crisis and resilience. BMJ Glob. Health 3, e000829-e000829 (2018). doi:10.1136/bmigh-2018-000829 Medline

4. G. Lotta, C. Wenham, J. Nunes, D. N. Pimenta, Community health workers reveal COVID-19 disaster in Brazil. Lancet 396, 365-366 (2020). doi:10.1016/S0140$6736(20) 31521-X$ Medline

5. L. G. Barberia, E. J. Gómez, Political and institutional perils of Brazil's COVID-19 crisis. Lancet 396, 367-368 (2020). doi:10.1016/S0140-6736(20)31681-0 Medline

6. S. Ferigato, M. Fernandez, M. Amorim, I. Ambrogi, L. M. M. Fernandes, R. Pacheco, The Brazilian Government's mistakes in responding to the COVID-19 pandemic. Lancet 396, 1636 (2020). doi:10.1016/S0140-6736(20)32164-4 Medline

7. A. K. Pereira, M. S. Oliveira, T. S. Sampaio, Heterogeneidades das políticas estaduais de distanciamento social diante da COVID-19: Aspectos políticos e técnico-administrativos. Rev. Adm. Pública 54, 678-696 (2020). doi:10.1590/0034-761220200323

8. A. Petherick, B. Kira, R. Goldszmidt, L. Barberia, "Do Brazil's COVID-19 government response measures meet the WHO's criteria for policy easing?" (University of Oxford, Blavatnik School of Government working paper, 2020);

https://www.bsg,ox.ac.uk/research/publications/do-brazils-covid-19government-response-measures-meet-whos-criteria-policy.

9. L. F. Buss, C. A. Prete Jr., C. M. M. Abrahim, A. Mendrone Jr., T. Salomon, C. de Almeida-Neto, R. F. O. França, M. C. Belotti, M. P. S. S. Carvalho, A. G. Costa, M. A. E. Crispim, S. C. Ferreira, N. A. Fraiij, S. Gurzenda, C. Whittaker, L. T. Kamaura, P. L. Takecian, P. da Silva Peixoto, M. K. Oikawa, A. S. Nishiya, V. Rocha, N. A. Salles, A. A. de Souza Santos, M. A. da Silva, B. Custer, K. V. Parag, M. Barral-Netto, M. U. G. Kraemer, R. H. M. Pereira, O. G. Pybus, M. P. Busch, M. C. Castro, C. Dye, V. H. Nascimento, N. R. Faria, E. C. Sabino, Three-quarters attack rate of SARS-CoV-2 in the Brazilian Amazon during a largely unmitigated epidemic. Science 371, 288 292 (2021). doi:10.1126/science. abe9728 Medline

10. P. Baqui, I. Bica, V. Marra, A. Ercole, M. van der Schaar, Ethnic and regional variations in hospital mortality from COVID-19 in Brazil: A cross-sectional observational study. Lancet Glob. Health 8, e1018-e1026 (2020). doi:10.1016/S2214-109X(20)30285-0 Medline

11. P. C. Hallal, F. P. Hartwig, B. L. Horta, M. F. Silveira, C. J. Struchiner, L. P. Vidaletti, N. A. Neumann, L. C. Pellanda, O. A. Dellagostin, M. N. Burattini, G. D. Victora, A. M. B. Menezes, F. C. Barros, A. J. D. Barros, C. G. Victora, SARS-CoV-2 antibody prevalence in Brazil: Results from two successive nationwide serological household surveys. Lancet Glob. Health 8, e1390-e1398 (2020). doi:10.1016/S2214-109X(20)30387-9 Medline

12. F. Ahmed, N. Ahmed, C. Pissarides, J. Stiglitz, Why inequality could spread COVID19. Lancet Public Health 5, e240 (2020). doi:10.1016/S2468-2667(20)30085-2 Medline

13. D. S. Candido, I. M. Claro, J. G. de Jesus, W. M. Souza, F. R. R. Moreira, S. Dellicour, T. A. Mellan, L. du Plessis, R. H. M. Pereira, F. C. S. Sales, E. R. Manuli, J. Thézé, L. Almeida, M. T. Menezes, C. M. Voloch, M. J. Fumagalli, T. M. Coletti, C. A. M. da Silva, M. S. Ramundo, M. R. Amorim, H. H. Hoeltgebaum, S. Mishra, M. S. Gill, L. M. Carvalho, L. F. Buss, C. A. Prete Jr., J. Ashworth, H. I. Nakaya, P. S. Peixoto, O. J. Brady, S. M. Nicholls, A. Tanuri, Á. D. Rossi, C. K. V. Braga, A. L. Gerber, A. P. de C Guimarães, N. Gaburo Jr., C. S. Alencar, A. C. S. Ferreira, C. X. Lima, J. E. Levi, C. Granato, G. M. Ferreira, R. S. Francisco Jr., F. Granja, M. T. Garcia, M. L. Moretti, M. W. Perroud Jr., T. M. P. P. Castiñeiras, C. S. Lazari, S. C. Hill, A. A. de Souza Santos, C. L. Simeoni, J. Forato, A. C. Sposito, A. Z. Schreiber, M. N. N. Santos, C. Z. de Sá, R. P. Souza, L. C. Resende-Moreira, M. M. Teixeira, J. Hubner, P. A. F. Leme, R. G. Moreira, M. L. Nogueira, N. M. Ferguson, S. F. Costa, J. L. ProencaModena, A. T. R. Vasconcelos, S. Bhatt, P. Lemey, C. H. Wu, A. Rambaut, N. J. Loman, R. S. Aguiar, O. G. Pybus, E. C. Sabino, N. R. Faria, Evolution and epidemic spread of SARS-CoV-2 in Brazil. Science 369, 1255-1260 (2020). doi:10.1126/science.abd2161 Medline

14. W. M. de Souza, L. F. Buss, D. D. S. Candido, J.-P. Carrera, S. Li, A. E. Zarebski, R. H. M. Pereira, C. A. Prete Jr., A. A. de Souza-Santos, K. V. Parag, M. C. T. D. Belotti, M. F. Vincenti-Gonzalez, J. Messina, F. C. da Silva Sales, P. D. S. Andrade, V. H. Nascimento, F. Ghilardi, L. Abade, B. Gutierrez, M. U. G. Kraemer, C. K. V. Braga, R. S. Aguiar, N. Alexander, P. Mayaud, O. J. Brady, I. Marcilio, N. Gouveia, G. Li, A. Tami, S. B. de Oliveira, V. B. G. Porto, F. Ganem, W. A. F. de Almeida, F. F. S. T.
Fantinato, E. M. Macário, W. K. de Oliveira, M. L. Nogueira, O. G. Pybus, C.-H. Wu, J. Croda, E. C. Sabino, N. R. Faria, Epidemiological and clinical characteristics of the COVID-19 epidemic in Brazil. Nat. Hum. Behav. 4, 856-865 (2020). doi:10.1038/s41562-020-0928-4 Medline

15. N. Kortessis, M. W. Simon, M. Barfield, G. E. Glass, B. H. Singer, R. D. Holt, The interplay of movement and spatiotemporal variation in transmission degrades pandemic control. Proc. Natl. Acad. Sci. U.S.A. 117, 30104-30106 (2020). doi:10.1073/pnas.2018286117Medline

16. M. Kulldorff, R. Heffernan, J. Hartman, R. Assunção, F. Mostashari, A space-time permutation scan statistic for disease outbreak detection. PLOS Med. 2, e59 (2005). doi:10.1371/journal.pmed.0020059 Medline

17. J. D. Y. Orellana, G. M. D. Cunha, L. Marrero, B. L. Horta, I. D. C. Leite, Explosion in mortality in the Amazonian epicenter of the COVID-19 epidemic 19. Cad. Saude Publica 36, e00120020 (2020). doi:10.1590/0102-311x00120020 Medline

18. S. Kim, M. C. Castro, Spatiotemporal pattern of COVID-19 and government response in South Korea (as of May 31, 2020). Int. J. Infect. Dis. 98, 328-333 (2020). doi:10.1016/ijiid.2020.07.004 Medline

19. O. T. Ranzani, L. S. L. Bastos, J. G. M. Gelli, J. F. Marchesi, F. Baião, S. Hamacher, F. A. Bozza, Characterisation of the first 250,000 hospital admissions for COVID19 in Brazil: A retrospective analysis of nationwide data. Lancet Respir. Med. 9 , 407-418 (2021). doi:10.1016/S2213-2600(20)30560-9 Medline

20. L. Kerr, C. Kendall, A. A. M. D. Silva, E. M. L. Aquino, J. M. Pescarini, R. L. F. Almeida, M. Y. Ichihara, J. F. Oliveira, T. V. B. Araújo, C. T. Santos, D. C. P. Jorge, D. B. Miranda Filho, G. Santana, L. Gabrielli, M. F. P. M. Albuquerque, N. Almeida-Filho, N. J. Silva, R. Souza, R. A. A. Ximenes, C. M. T. Martelli, S. P. Brandão Filho, W. V. Souza, M. L. Barreto, COVID-19 in Northeast Brazil: achievements and limitations in the responses of the state governments. Cien. Saude Colet. 25(suppl 2), 40994120 (2020). doi:10.1590/1413-812320202510.2.28642020 Medline

21. E. M. Hoover Jr., Interstate redistribution of population, 1850-1940. J. Econ. Hist. 1, 199-205 (1941). doi:10.1017/S0022050700052980

22. P. A. Rogerson, D. A. Plane, The Hoover index of population concentration and the demographic components of change: An article in memory of Andy Isserman. Int. Reg. Sci. Rev. 36, 97-114 (2012). doi:10.1177/0160017612440811

23. G. S. Costa, W. Cota, S. C. Ferreira, Outbreak diversity in epidemic waves propagating through distinct geographical scales. Phys. Rev. Res. 2, 043306 (2020). doi:10.1103/PhysRevResearch.2.043306

24. T. McCoy, "Rio's governor suspended amid widening corruption probe involving Brazil's pandemic response," Washington Post, 28 August 2020; https://www.washingtonpost.com/world/the_americas/brazil-coronaviruscorruption-rio/2020/08/28/fe213756-e918-11ea-970a$64 \mathrm{c} 73 \mathrm{alc} 2392$ story $\mathrm{html}$

25. G. James, D. Witten, T. Hastie, R. Tibshirani, An Introduction to Statistical Learning with Applications in R (Springer, 2017).

26. Instituto Brasileiro de Geografia e Estatistica, Regiões de Influência das Cidades: 2018 (IBGE, Coordenação de Geografia, 2020)

27. C. Pereira, A. Medeiros, F. Bertholini, Fear of death and polarization: Political consequences of the COVID-19 pandemic. Rev. Adm. Pública 54, 952-968 (2020).

28. The Lancet, Genomic sequencing in pandemics. Lancet 397, 445 (2021). doi:10.1016/S0140-6736(21)00257-9 Medline

29. N. R. Faria, T. A. Mellan, C. Whittaker, I. M. Claro, D. S. da Candido, S. Mishra, M. A E. Crispim, F. C. Sales, I. Hawryluk, J. T. McCrone, R. J. G. Hulswit, L. A. M. Franco, M. S. Ramundo, J. G. de Jesus, P. S. Andrade, T. M. Coletti, G. M. Ferreira, C. A. M. Silva, E. R. Manuli, R. H. M. Pereira, P. S. Peixoto, M. U. Kraemer, N. Gaburo Jr., C. C. da Camilo, H. Hoeltgebaum, W. M. Souza, E. C. Rocha, L. M. de Souza, M. C. de Pinho, L. J. T Araujo, F. S. V. Malta, A. B. de Lima, J. P. do Silva, D. A. G. Zauli, A. C. S. de Ferreira, R. P. Schnekenberg, D. J. Laydon, P. G. T. Walker, H. M. Schlüter, A. L. P. dos Santos, M. S. Vidal, V. S. Del Caro, R. M. F. Filho, H. M. dos Santos, R. S. Aguiar, J. L. P. Modena, B. Nelson, J. A. Hay, M. Monod, X. Miscouridou, H. Coupland, R. Sonabend, M. Vollmer, A. Gandy, M. A. Suchard, T. A. Bowden, S. L. K. Pond, C.-H. Wu, O. Ratmann, N. M. Ferguson, C. Dye, N. J. Loman, P. Lemey, A. Rambaut, N. A. Fraiji, M. P. S. S. do Carvalho, O. G. Pybus, S. Flaxman, S. Bhatt, E. C. Sabino, Genomics and epidemiology of a novel SARS-CoV-2 lineage in Manaus, Brazil. medRxiv 2021.2002.2026.21252554 [Preprint]. 3 March 2021 https://doi.org/10.1101/2021.02.26.21252554 
30. Observatório Covid-19 Fiocruz, "Fiocruz detecta mutação associada a variantes de preocupação do Sars-Cov-2 em diversos estados do país" (Observatório Covid-19 Fiocruz, 2021);

https:/portal.fiocruz.br/sites/portal.fiocruz.br/files/documentos/comunicado variantes_de_preocupacao_fiocruz_22021-03-04.pdf.

31. T. Phillips, "Covid eruption in Brazil's largest state leaves health workers begging for help," The Guardian,

14 January 2021; https:/www.theguardian.com/world/2021/jan/14/brazilmanaus-amazonas-covid-coronavirus.

32. Data and code for:M. C. Castro, S. Kim, L. Barberia, A. Freitas Ribeiro, S. Gurzenda, K. Braga Ribeiro, E. Abbott, J. Blossom, B. Rache, B. H. Singer, Spatiotemporal pattern of COVID-19 spread in Brazil, Zenodo (2021). https://doi.org/10.5281/zenodo.4606715.

33. R. Lovelace, R. Ellison, stplanr: A package for transport planning. R J. 10, 7-23 (2018). doi:10.32614/RJ-2018-053

34. G. M. Steeves, F. C. Petterini, G. V. Moura, The interiorization of Brazilian violence, policing, and economic growth. Economia 16, 359-375 (2015). doi:10.1016/i.econ.2015.09.003

35. L. G. Barberia, Replication Data for: COVID-19 Government Response Tracker for the Brazilian Federation (CGRT-BRFED), Harvard Dataverse (2021). https://doi.org/10.7910/DVN/IPLLX

36. R. Tibshirani, G. Walther, T. Hastie, Estimating the number of clusters in a data set via the gap statistic. J. R. Stat. Soc. Series B Stat. Methodol. 63, 411-423 (2001). doi:10.1111/1467-9868.00293

37. A. D. Gordon, "Null models in cluster validation," in From Data to Knowledge, W. Gaul, D. Pfeifer, Eds. (Springer, 1996), pp. 32-44.

\section{ACKNOWLEDGMENTS}

Funding: Harvard TH Chan School of Public Health (MCC research funds). Author contributions: Conceptualization - MCC. Methodology - MCC. Software - SK, $\mathrm{JB}$, and EA. Formal analysis - MCC, SK, SG, LB, AFR, EA, JB, and BR. Interpretation - MCC and BHS. Data curation - MCC, LB, KBR, SK, and SG. Drafting - MCC. Review and editing - all authors. Visualization - MCC, JB, and SK. Funding - MCC. Competing interests: The authors declare no competing interests. Data and materials availability: The data and code required to reproduce the results in this article can be found on Zenodo (32). Since data were de-identified this study did not involve human subjects. We thank In Loco for making available their Social Distancing Index. This work is licensed under a Creative Commons Attribution 4.0 International (CC BY 4.0) license, which permits unrestricted use, distribution, and reproduction in any medium, provided the original work is properly cited. To view a copy of this license, visit https://creativecommons.org/licenses/by/4.0/. This license does not apply to figures/photos/artwork or other content included in the article that is credited to a third party; obtain authorization from the rights holder before using such material.

\section{SUPPLEMENTARY MATERIALS}

science sciencemag.org/cgi/content/full/science.abh1558/DC1

Materials and Methods

Figs. S1 to S3

Tables S1 to S14

References (33-37)

Movies S1 and S2

MDAR Reproducibility Checklist

18 February 2021; accepted 9 April 2021

Published online 14 April 2021

10.1126/science.abh1558 

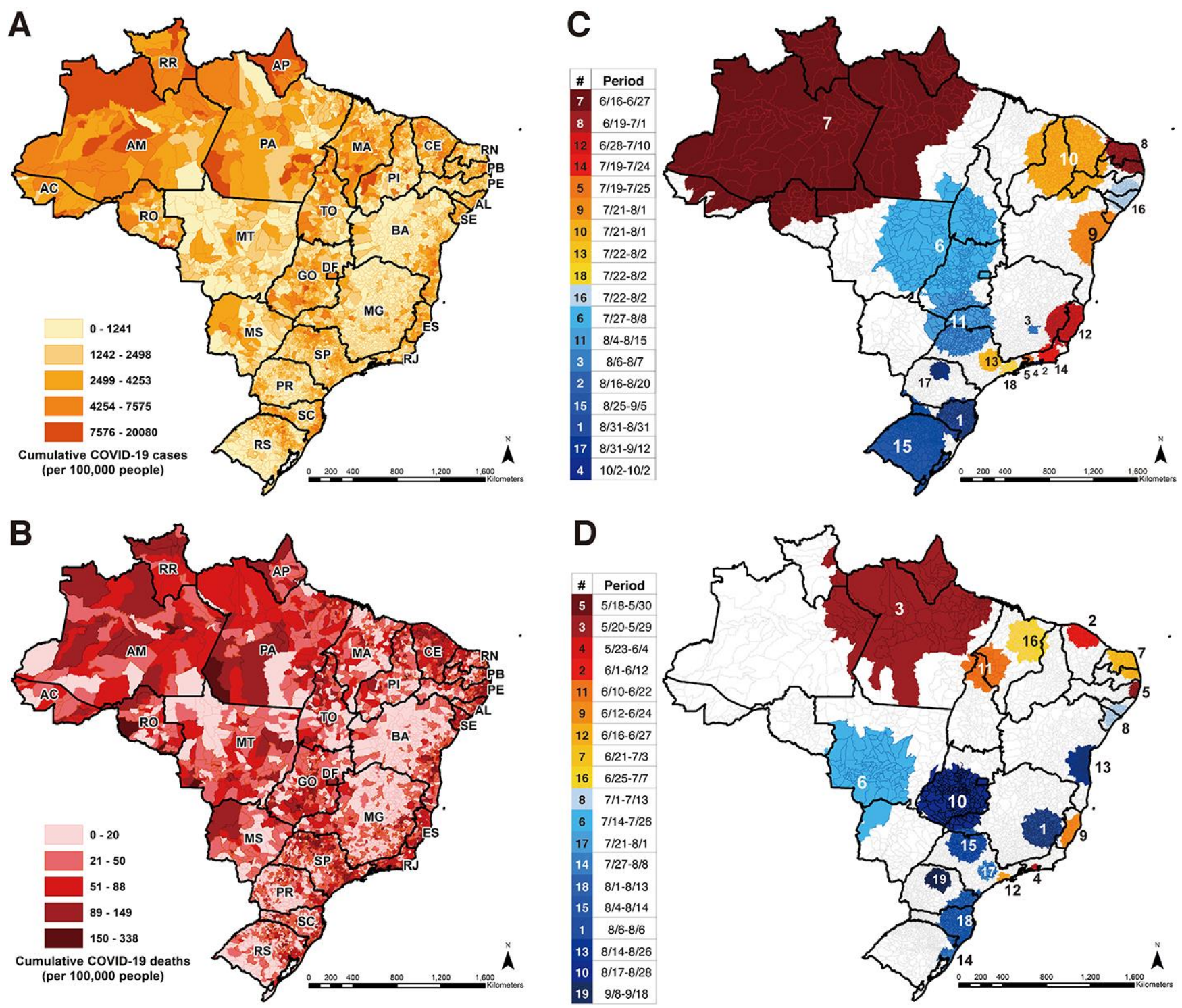

Fig. 1. Spatial distribution and clustering of reported COVID-19 cases and deaths. Cumulative number of COVID19 cases (A) and deaths (B) per 100,000 people by municipality. Dark lines on the maps show state boundaries. State acronyms by region, North: $\mathrm{AC}=\mathrm{Acre}, \mathrm{AP}=\mathrm{Amapá}, \mathrm{AM}=$ Amazonas, $\mathrm{PA}=$ Pará, $\mathrm{RO}=$ Rondônia, RR=Roraima, and $\mathrm{TO}=$ Tocantins; Northeast: $\mathrm{AL}=$ Alagoas, $\mathrm{BA}=$ Bahia, $\mathrm{CE}=$ Ceará, $\mathrm{MA}=$ Maranhão, $\mathrm{PB}=$ Paraíba, $\mathrm{PE}=$ Pernambuco, $\mathrm{PI}=$ Piauí, $\mathrm{RN}=$ Rio Grande do Norte, and SE=Sergipe; Center-West: DF=Distrito Federal, GO=Goiás, MT=Mato Grosso, and MS=Mato Grosso do Sul; Southeast: ES=Espírito Santo; MG=Minas Gerais; RJ=Rio de Janeiro; and SP=São Paulo; South: PR=Paraná; RS=Rio Grande do Sul; and SC=Santa Catarina. Spatio-temporal clustering of cases (C) and deaths (D) across Brazilian municipalities. Color and number codes in the clusters and the table on the left are the same, and the table indicates the interval during which each cluster was statistically significant. The color gradient (dark red to dark blue) indicates the temporal change based on the initial date of the cluster, and the cluster number indicates the rank of the relative risk for each cluster (tables S2 and S3). Clusters were assessed with the space-time scan statistic (see supplementary materials). 
A

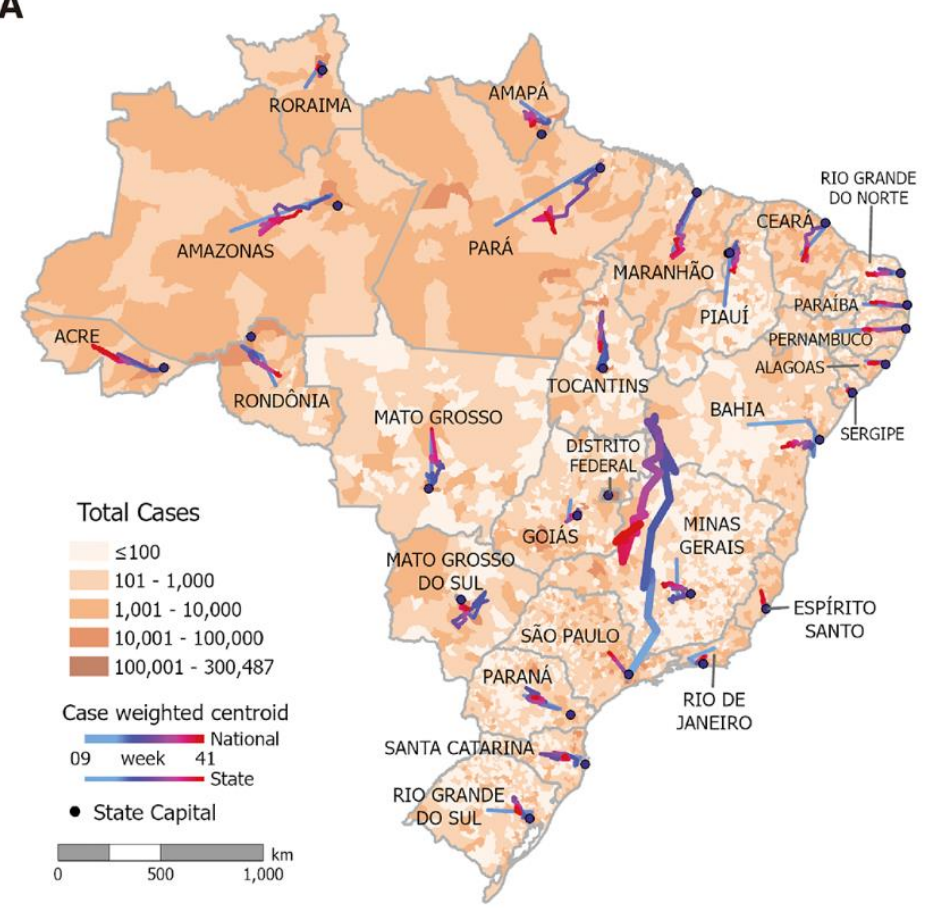

C

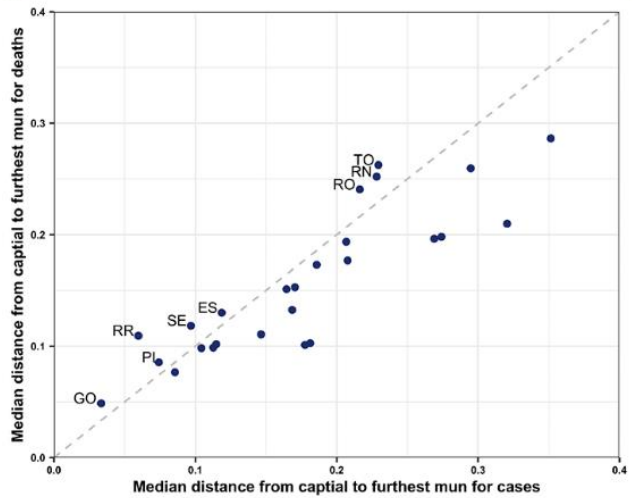

B

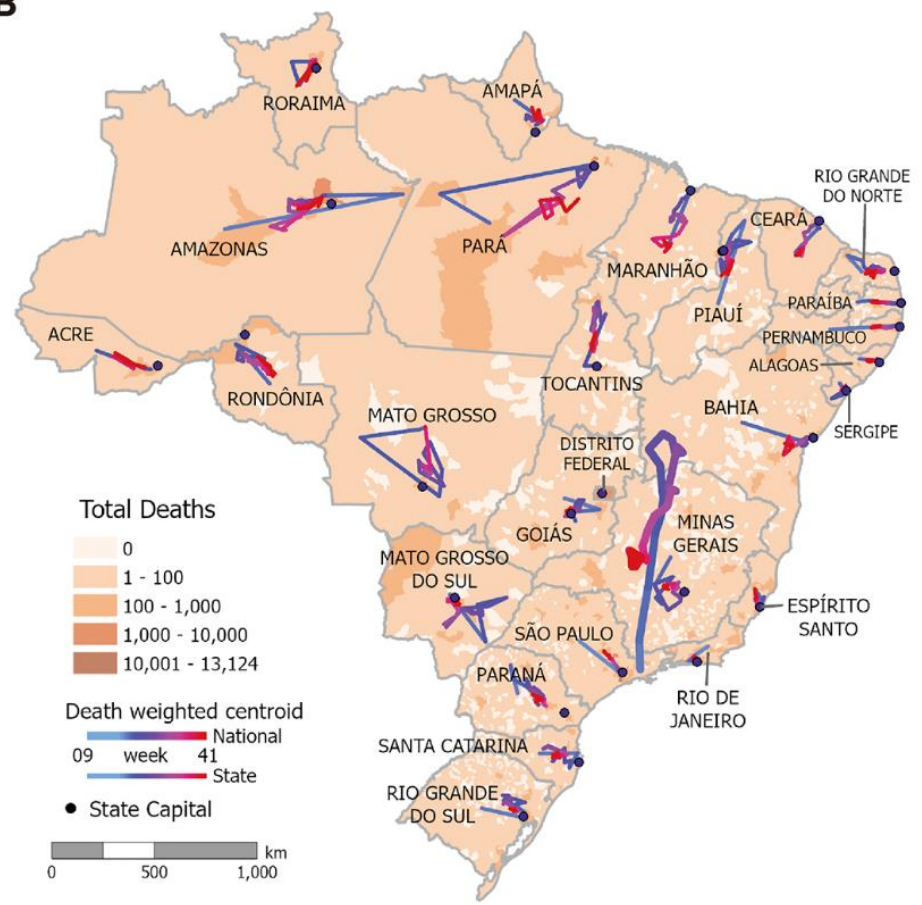

E
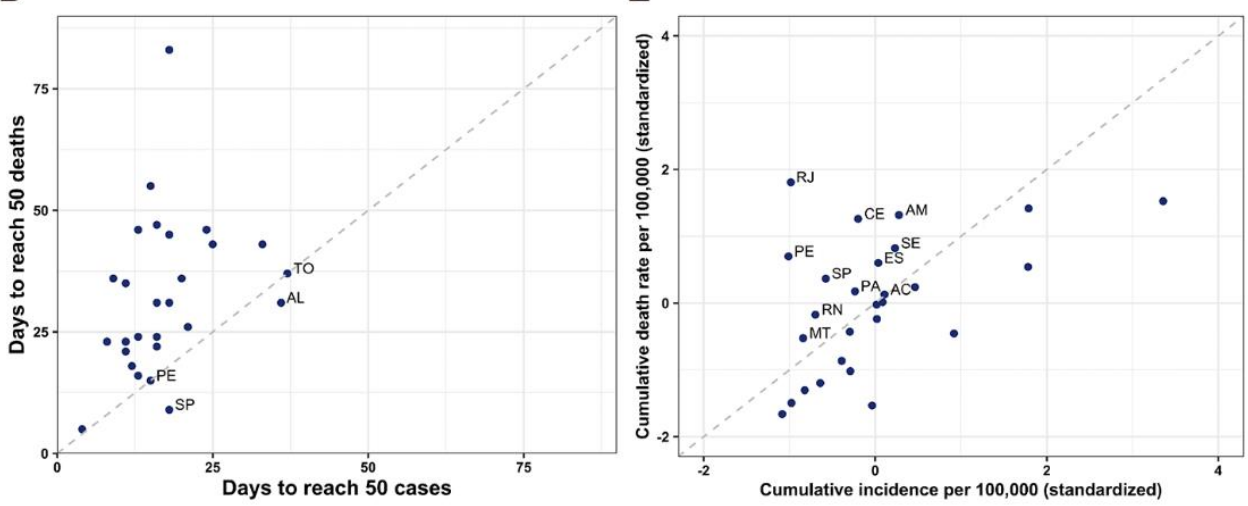

Fig. 2. Spatial and temporal spread of COVD-19 cases and deaths. COVID-19 case- (A) and death-weighted (B) geographic centers by epidemiological week. Thick lines show the geographic center for Brazil, thin lines show the trajectory of the center in each state, and the black dot indicates the state capital city (see supplementary materials). The first case in each state was recorded in the capital city, except for Rio de Janeiro, Rondônia, Bahia, Minas Gerais, and Rio Grande do Sul, and thus the trajectory of the center starts in the interior. This was more common for deaths (14 states did not report the first death in the capital: Rio de Janeiro, Amazonas, Pará, Piauí, Rio Grande do Norte, Paraíba, Espírito Santo, Paraná, Santa Catarina, Mato Grosso do Sul, Mato Grosso, and Goiás). Figure S2 shows detailed maps for each state. (C) Scatterplot of the median distance that the geographical center of cases (X-axis) and deaths (Y-axis) shifted weekly in each state (measured as the ratio of the distance that the geographical center of cases shifted weekly in each state to the distance between the capital city and the furthest municipality in the state). (D) Scatterplot of the number of days that it took for a state to reach 50 COVID-19 cases (X-axis) after the first case was reported and 50 deaths after the first COVID-19 confirmed death (Y-axis). (E) Scatterplot of the standardized number of cases per 100,000 people (X-axis) and deaths per 100,000 people (Y-axis) by state. The 45-degree lines in (C), (D), and (E) describe equal values for variables in the scatterplot. 
A
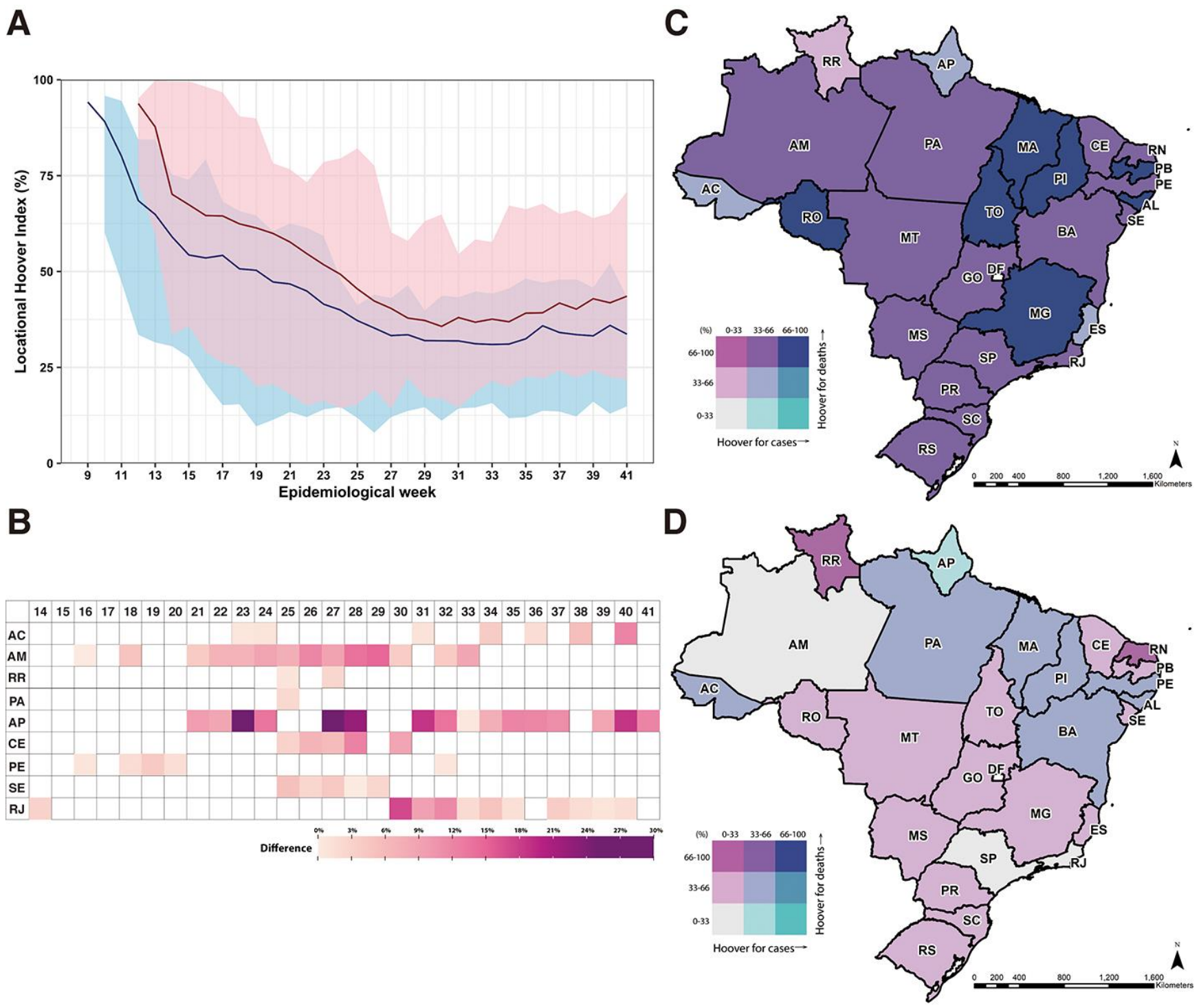

Fig. 3. Spread of COVID-19 cases and deaths. (A) Locational Hoover index (see supplementary materials) for cases (blue line) and deaths (red line) by epidemiological week. The area around each curve indicates the maximum and minimum index observed across states. (B) States and weeks when the locational Hoover index for cases was bigger than the index for deaths, indicating a faster spread of deaths. Bivariate choropleth map of the locational Hoover Index for cases and deaths in epidemiological week 14 (March 29-April 4) (C) and epidemiological week 41 (October 4-10) (D). Since SARS-CoV-2 reached states at different epidemiological weeks, (C) shows data from week 12 for RJ and SP; week 13 for AM, PI, RN, PE, PR, SC, RS, and GO; week 15 for AC; and week 16 for TO. Similarly, (D) shows data for week 33 for MT, and week 39 for ES. 
A

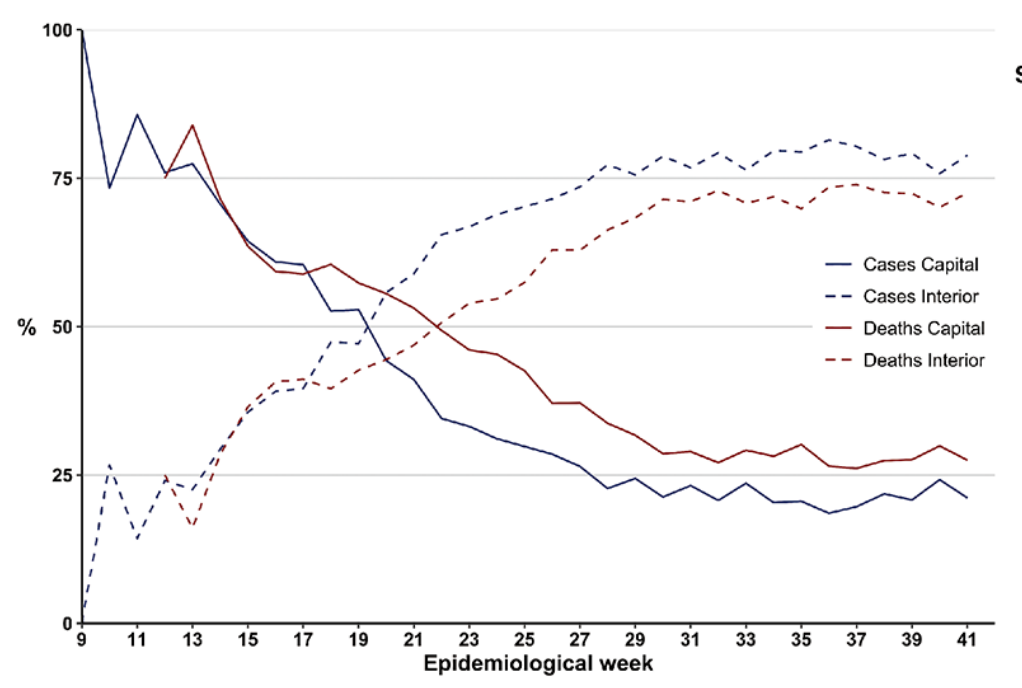

C

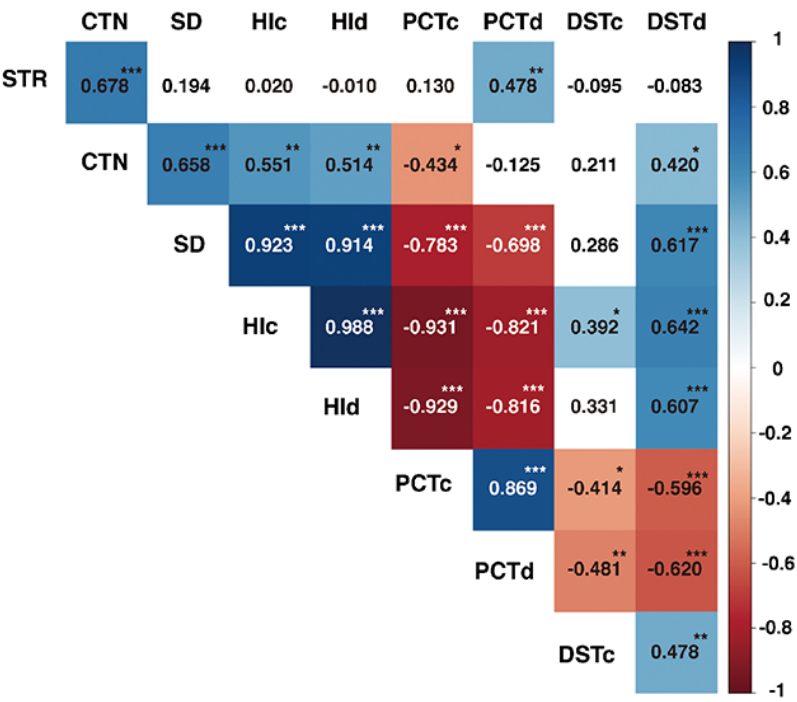

B
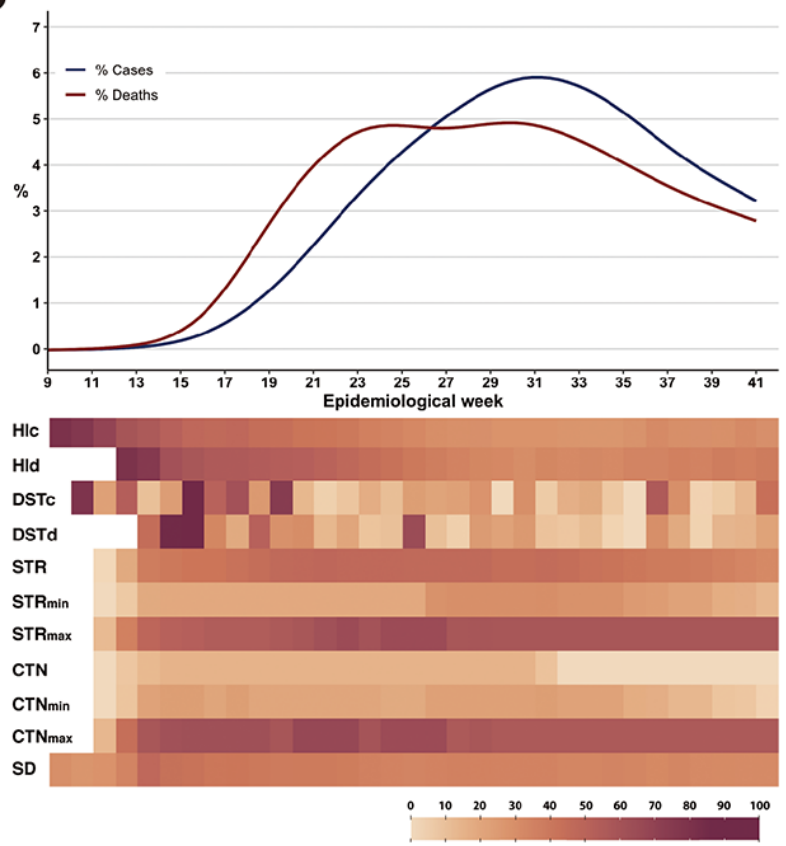

D

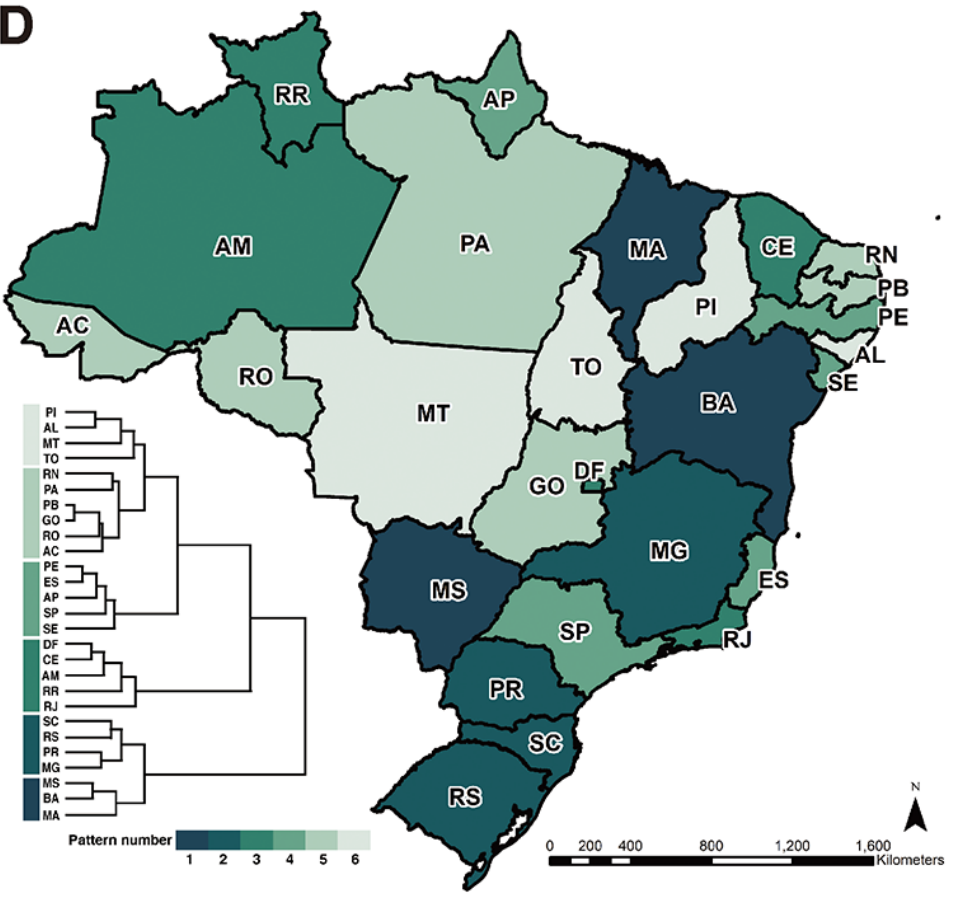

Fig. 4. Indicators of COVID-19 spread and response measures. (A) Percentage of cases (blue lines) and deaths (red lines) in the state capitals (solid lines) and the remaining municipalities (dashed lines) by epidemiological week. (B) Percentage of reported COVID-19 cases and deaths, and selected variables by epidemiological week. Variables: Stringency Index (STR), Containment Index (CTN), Social Distancing Index (SD), locational Hoover Index for cases (HIc), locational Hoover Index for deaths (HId), percentage of cases in each epidemiological week (PCTc), percentage of deaths in each epidemiological week (PCTd), normalized distance by which the national geographical center of cases shifted in each week (DSTc), and normalized distance by which the national geographical center of deaths shifted in each week (DSTd). Distances were normalized to vary between 0 and 100 . The subscript min indicates the minimum value of the index observed among all states in each week; the subscript max denotes the maximum value. (C) Correlation matrix (Pearson). Cells in shades of red or blue are statistically significant: ${ }^{*}<0.05$, $* *<0.01$, and $*^{* *}<0.001$. (D) Hierarchical clustering dendrogram by state based on five variables: cumulative deaths per 100,000 people, maximum percentage of deaths in a week, maximum SD, epidemiological week when HId became lower than 50 , and the maximum value of effective $R_{t}$ over the study period (see supplementary materials). 